\title{
Conservative Approach for Treatment of Isolated Mandibular Fractures, the Adaptations During COVID 19 Pandemic
}

\author{
Daniel Sathiya Sundaram Selvaraj ${ }^{1}$ (D) Ajish George Oommen ${ }^{1} \cdot$ D. Jenifer ${ }^{1}$. \\ G. Vinitha ${ }^{1} \cdot$ Jagadish Ebenezer $^{1}$
}

Received: 21 August 2020/Accepted: 27 November 2020/Published online: 3 January 2021

(C) The Association of Oral and Maxillofacial Surgeons of India 2021

\begin{abstract}
Background The ongoing COVID 19 pandemic brought about a sudden disruption to the way medical services are rendered in our country. Management of maxillofacial injuries, especially isolated mandibular fractures by surgical methods, became near impossibility because of the restrictions and other concerns related to the pandemic.

Methods The individuals who suffered isolated mandibular fracture because of trauma were included, to undergo conservative treatment methods with adaptations for the pandemic. Individuals with multiple bone fractures were excluded, and the selected patients were given the choice to opt out from this treatment plan. We followed a more conservative approach with adaptations, which we have discussed in this article.

Result The fracture healing for all the patients was as expected, and none of our team members got infected with this virus from exposure to patients.

Conclusion The adaptations helped in limiting the possible exposure of patients, relatives and health care providers to the virus and addressed other pressing concerns related to this pandemic. We present the guideline that we formulated in our unit, which we used to manage the patients who reported to us with isolated mandibular fractures during the ongoing pandemic.
\end{abstract}

Keywords COVID 19 - Pandemic - Isolated mandibular fracture $\cdot$ Adaptations

Daniel Sathiya Sundaram Selvaraj

danielvellore@gmail.com

1 Department of Dental and Oral Surgery-Unit 2, Christian Medical College and Hospital, Vellore, Tamil Nadu, India

\section{Introduction}

Mandibular fractures are most often treated by open reduction and internal fixation (ORIF) unless age, fracture site and other comorbidities necessitate a change in the treatment plan $[1,2]$. Intermaxillary fixation (IMF) using arch bars and wires or acrylic splints are done to reduce and immobilize when ORIF is not possible [3, 4]. However, during the COVID 19 lockdown period, apart from the usual clinical conditions that determine the treatment plan for mandibular fractures, the nature of spread of the virus and the restrictions enforced during the lockdown led to a modified and more conservative method of treatment [5], which would not have been followed otherwise.

The adaptations happened because of the constraints due to the pandemic. The government had imposed travel restrictions though travel for medical emergencies was permitted. During the initial days of the pandemic, lack of clear guidelines, and "dissuasive" restrictions laid down by the government to test a patient for COVID 19, discouraged the health care team from undertaking certain procedures, which were not really lifesaving. There were apprehensions of a disease spread while intubating during general anesthesia, which is an aerosol-generating procedure, from a possibly infected patient but who had not been tested. This resulted in a restricted use of operating theatres only for life saving procedures [6]. The ministry of health and family welfare (MOHFW) in India had also advised similarly for utilization of operating theatres through an advisory dated 22 March 2020 [7]. Another advisory on Guidelines for Dental Professionals in COVID 19 pandemic situation was released on 19 May 2020 which referred to Facial bone trauma as an emergency condition [8]. However, for the period between 22 March and 19 May, a good 2 months, operating an isolated mandibular 
Table 1 Distribution of facial trauma

\begin{tabular}{llllll}
\hline $\begin{array}{l}\text { Total patients } \\
\text { with facial injury }\end{array}$ & $\begin{array}{l}\text { Soft tissue } \\
\text { facial injury }\end{array}$ & $\begin{array}{l}\text { Isolated } \\
\text { mandibular } \\
\text { fracture }\end{array}$ & $\begin{array}{l}\text { Mandibular fracture } \\
\text { with other bone fracture }\end{array}$ & $\begin{array}{l}\text { Non-surgical management for } \\
\text { isolated mandibular fracture }\end{array}$ & $\begin{array}{l}\text { Surgical management for } \\
\text { isolated mandibular fracture }\end{array}$ \\
\hline 63 & 39 & 19 & 5 & 16 & 3 \\
\hline
\end{tabular}

Table 2 Breakup of the non-surgical management

\begin{tabular}{|c|c|c|c|c|c|}
\hline $\begin{array}{l}\text { IMF with } \\
\text { eyelets }\end{array}$ & $\begin{array}{l}\text { IMF with arch bars in } \\
\text { both arches }\end{array}$ & $\begin{array}{l}\text { IMF with eyelets in the upper arch and arch } \\
\text { bar in the lower arch }\end{array}$ & $\begin{array}{l}\text { Only lower arch bar } \\
\text { without IMF }\end{array}$ & $\begin{array}{l}\text { Only bridle wiring } \\
\text { without IMF }\end{array}$ & $\begin{array}{l}\text { Nil } \\
\text { intervention }\end{array}$ \\
\hline 5 & 3 & 1 & 2 & 2 & 3 \\
\hline
\end{tabular}

fracture terming it as an emergency was a rather debatable decision, especially when a more conservative method of treatment was available in the form of IMF. Further, the dearth of personal protective equipment (PPE) not only in India but world over [9], and the strain on health care services as the pandemic progressed into months, in the form of non-availability inpatient beds, altered our treatment planning for isolated mandibular fractures and tilted it toward a more conservative method.

\section{Materials and Methods}

All the patients who were referred to our unit from the accident and emergency department between 25 March 2020 and 18 Aug 2020, with isolated mandibular fractures were treated according to the guidelines that we had formed. Patients with mandibular fracture along with maxillary fracture or other bone fractures were not treated according to this guideline. Patients were informed about the surgical and non-surgical treatment options for fixing the isolated mandibular fractures. They being aware of the restrictions imposed by the government and the risks and difficulties associated in being admitted as an inpatient, as perceived by them, chose the treatment option. We then followed our guideline to execute the treatment.

\section{Results}

Sixty-three patients reported to the accident and emergency department during this period when our unit was on call, with facial injuries. Of these 39 had only soft injuries. The remaining 24 had hard tissue injuries of which five had mandibular fractures along with other bone fractures. Of the five patients who had mandibular fracture along with other bone fractures, we did open reduction and internal fixation (ORIF) for two patients as a combined surgery with other surgical departments (Table 1). The other three did not report to us for treatment.

The option of surgical or non-surgical method of treatment was left to the adequately informed patient. Sixteen of the nineteen patients opted for non-surgical management (Table 2). The other three opted for surgical management, which is ORIF for the isolated mandibular fracture.

\section{Discussion}

Treatment protocols for maxillofacial injuries evolved during the two world wars [10, 11], which were major disruptive global events. This pandemic has been one such, which has influenced almost all walks of life. Medical treatment has been no exception. Treatment of mandibular fractures also had to have a deviation from the conventional methods [12], and had to be thoughtfully planned to factor in all the imposed restraints and constraints. Therefore, in the prevailing scenario, we had to adopt a few modifications in the treatment methods. So we came up with certain criteria which would govern our treatment, and they became our guideline in the management of isolated mandibular fractures during this period which were,

1. Abide by the government's and local administrative authorities' advisories to health care facilities

2. Minimize the chances of exposure for the patient and care giver/relatives to the virus

3. Reduce the exposure time of the health care provider to the patient

4. Bring down the strain on the health care facility

5. Ease the financial stress on the patient during this pandemic brought economic crisis.

Following this guideline meant, we had to treat as far as possible, patients with an isolated mandibular fracture as an outpatient. This helped us fulfill all the criteria in our 
guideline. We were able to address the concerns of the patient, the treating surgeon and the health care facility with regard to the pandemic through our adaptations in our treatment plan.

\section{Concerns Related to the Patient}

On account of being treated as outpatients, the patient's relatives or caregivers did not have to travel back and forth to the hospital and their home during the government-imposed travel restrictions, which they would have done, had the patient been admitted. This reduced the chance of exposure of the caregivers/family members to the virus by visiting a health care facility frequently and the shear difficulty of travelling when strict lockdown was enforced.

We did not review the patient on IMF every week as we would normally do for six weeks instead, and we reviewed the patient once on the third week of IMF and then on the sixth week to remove the IMF. Holmes et al. [12] also took a similar kind of decision and referred the patients to the general practitioner (GP), but they also highlighted the difficulties of such a move.

One lady in her second trimester of pregnancy suffered a left parasymphysis fracture. We put her on IMF with arch bars and elastics considering her morning sickness. However, the episodes of vomiting were too frequent, which meant she had to be admitted, or she would have to travel daily to our center to have elastics placed again. The strict lock down, and possibility of increased risk of exposure to the virus through travel and frequenting the health care facility, forced us to do something, which we would not have done otherwise. We only placed the lower arch bar, across the fracture site thus stabilizing the segments, without putting her into IMF. She was explained that the outcome may not be satisfactory, and after the postpartum period, she may have to undergo a corrective surgery. At the end of six weeks, when we removed the arch bar she had no segmental mobility, but her occlusion was deranged.

By incorporating these adaptations, we addressed the concerns of the patients and their relatives by reducing the travel and possible risk of exposure to the virus.

\section{Concern Related to the Surgeon}

There was another young man, 23 years of age who had an undisplaced right parasymphysis fracture of the mandible. We placed an arch bar for the lower arch alone without putting him into IMF. Since the fracture was in the anterior region of the mandible close to the midline which is subjected to rotational forces [13], we did not do bridle wiring alone as we had supposed to do, rather we placed an arch bar in the lower arch but did not put him into IMF. After six weeks when we removed the arch bar, he had no segmental mobility. This considerably reduced the exposure time of the surgeon to the patient.

Through the course of the pandemic, we made a decision change to shift to the use of eyelets and bridle wires instead of arch-bars to do IMF (Fig. 1). We used eyelets for five of the nine patients who had minimally displaced fracture segments to achieve intermaxillary fixation. The sites of fracture for these patients are mentioned in the first column of Table 3 . This considerably reduced the exposure time of the surgeon to the patient. World Health Organization (WHO) in its scientific brief "Transmission of SARS-CoV-2: implications for infection prevention precautions" dated 9 July 2020 [14] mentioned about the length of exposure time, saying prolonged exposure increases the risk of transmission. Surprisingly most of the published literature, which suggests methods of practicing safe dentistry during this COVID 19 pandemic [15-17], does not mention about the necessity to adopt methods which will reduce the treatment time. Reduction in treatment time to as minimum as possible reduces the exposure time of the doctor [12] to a possibly infected patient. This formed the basis for our using eyelets instead of arch bars to achieve IMF. We did use arch bars in the upper and lower jaw to do IMF for three patients. Two of them had fractures at more than one site as indicated in second column of Table 3, and the segments were severely displaced. Though one patient had a right parasymphysis fracture alone, we had used arch bars as we were in the early stages of the pandemic and by then we had not made the decision change to shift to eyelets for IMF. Moreover, we preferred arch bars when we felt the need for guiding elastics to achieve occlusion. At the end of six weeks when the IMF was released, clinically all the patients fared well in terms of absence of segmental mobility and occlusion.

One patient suffered an undisplaced symphysis fracture of the mandible along with a right condylar head fracture. We decided to put him on IMF for two weeks only, to avoid the risk of temporomandibular joint ankylosis. We placed eyelets in the upper jaw and arch bars in the lower jaw to achieve IMF (Fig. 2). This decision to place eyelets in the upper jaw reduced the exposure time of the surgeon to the patient. Placing arch bar in the lower jaw provided greater the stability and immobilization for the symphysis fracture, which will experience rotational forces once we had released the IMF after 2 weeks, rather than a bridle wire alone as would have been the case had we used eyelets for the lower arch. We planned to retain the arch bar in the lower jaw for another four weeks after the initial two weeks of IMF.

We did only bridle wiring for two patients. They were not subjected to IMF. One patient had a minimally displaced right body of the mandible fracture. He reported to 


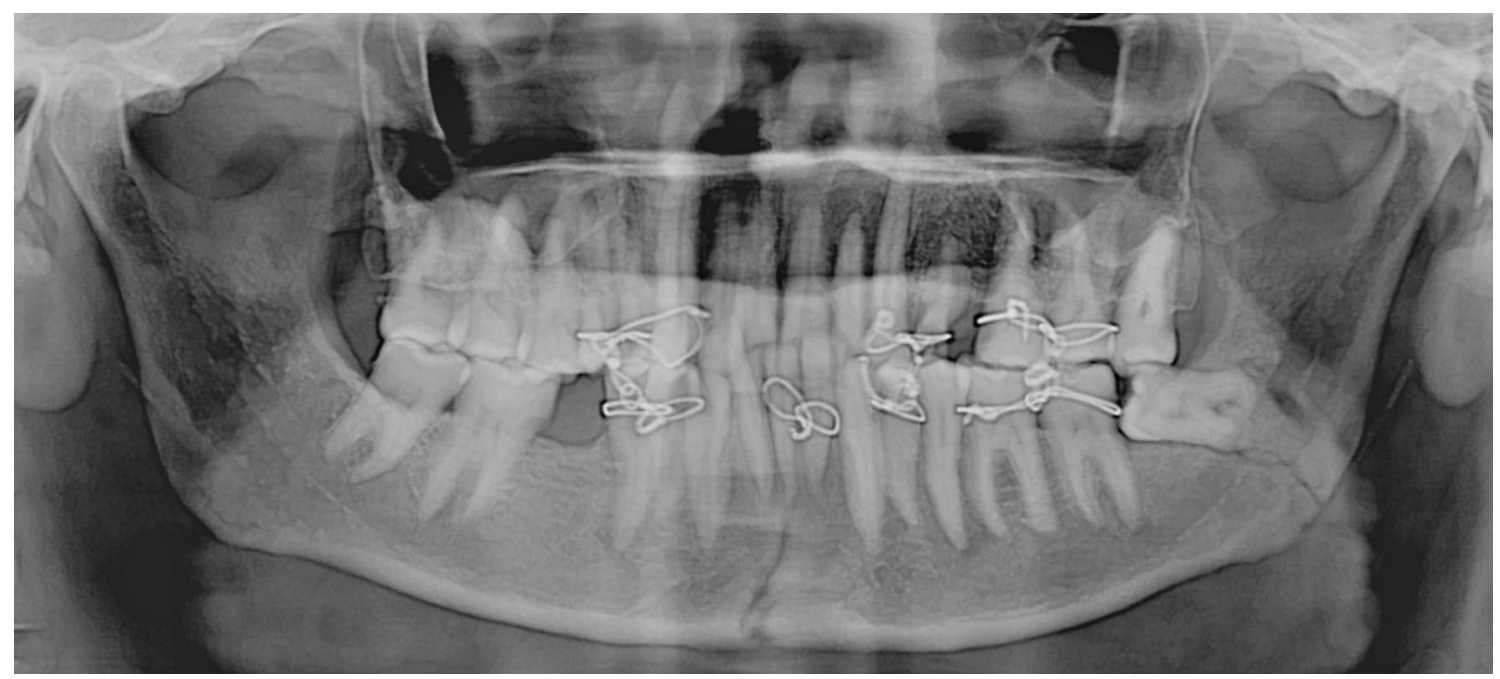

Fig. 1 IMF with eyelets and a bridle wire for symphysis and left angle of the mandible fracture

Table 3 List of patients according to fracture sites managed under each treatment method

\begin{tabular}{|c|c|c|c|c|c|c|}
\hline & IMF with eyelets & $\begin{array}{l}\text { IMF with arch bars } \\
\text { in both arches }\end{array}$ & $\begin{array}{l}\text { IMF with eyelets in the upper arch } \\
\text { and arch bar in the lower arch }\end{array}$ & $\begin{array}{l}\text { Only lower arch } \\
\text { bar without IMF }\end{array}$ & $\begin{array}{l}\text { Only bridle } \\
\text { wiring without } \\
\text { IMF }\end{array}$ & $\begin{array}{l}\text { Nil } \\
\text { intervention }\end{array}$ \\
\hline 1 & $\begin{array}{l}\text { Left angle and } \\
\text { symphysis }\end{array}$ & $\begin{array}{l}\text { Right } \\
\text { parasymphysis } \\
\text { and right ramus }\end{array}$ & $\begin{array}{l}\text { Left parasymphysis and right } \\
\text { condylar head }\end{array}$ & $\begin{array}{l}\text { Right } \\
\text { parasymphysis }\end{array}$ & $\begin{array}{l}\text { Right } \\
\text { parasymphysis }\end{array}$ & $\begin{array}{l}\text { Left } \\
\text { subcondylar }\end{array}$ \\
\hline 2 & $\begin{array}{l}\text { Right subcondylar and } \\
\text { right parasymphysis }\end{array}$ & $\begin{array}{l}\text { Right } \\
\text { parasymphysis }\end{array}$ & & $\begin{array}{l}\text { Left } \\
\text { parasymphysis } \\
\text { (pregnancy) }\end{array}$ & Right body & $\begin{array}{l}\text { Left } \\
\text { subcondylar }\end{array}$ \\
\hline 3 & Left parasymphysis & $\begin{array}{l}\text { Left angle and } \\
\text { symphysis }\end{array}$ & & & & $\begin{array}{l}\text { Left condylar } \\
\text { neck }\end{array}$ \\
\hline 4 & $\begin{array}{l}\text { Bilateral } \\
\text { parasymphysis }\end{array}$ & & & & & \\
\hline 5 & Left parasymphysis & & & & & \\
\hline
\end{tabular}

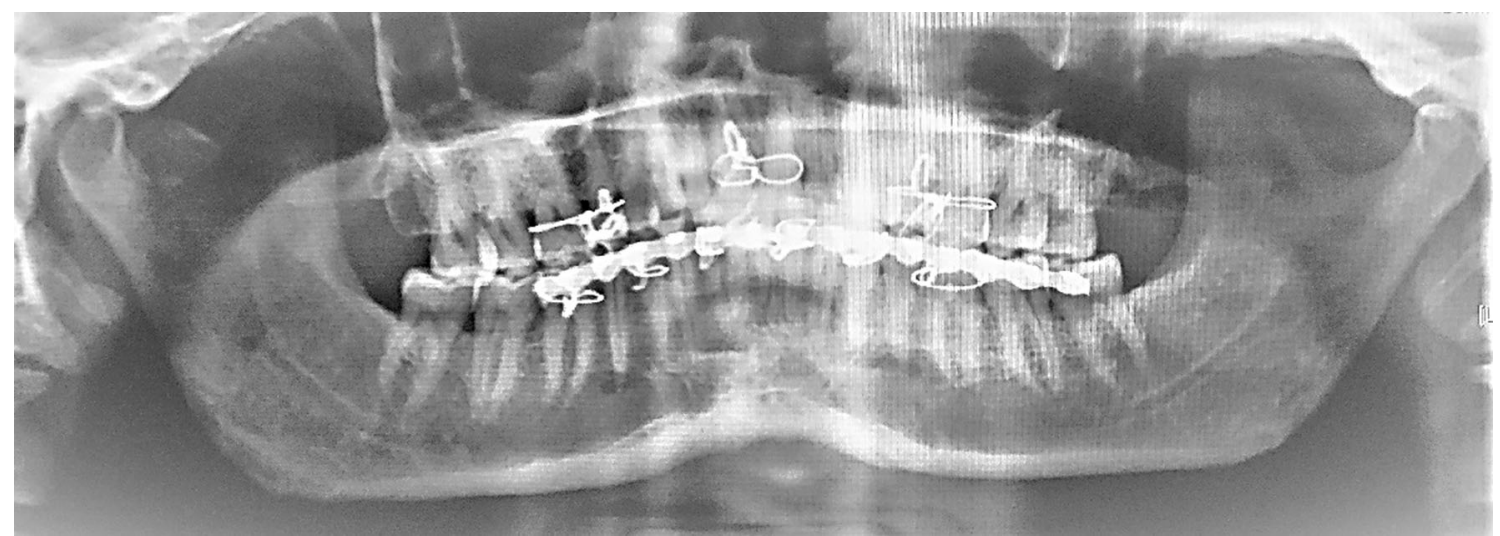

Fig. 2 IMF done with eyelets in the upper arch and arch bar in the lower arch

us about two weeks after the trauma. The segmental mobility was minimal, and his occlusion was minimally deranged. There are no rotational forces acting at the body of mandible, explained well by Koshy et al. [13]. We found that after reducing the mandible to perfect occlusion by asking him to clench as tight as possible, a bridle wire alone was enough for immobilization (Fig. 3). The reduction of exposure time of the surgeon to the patient is 


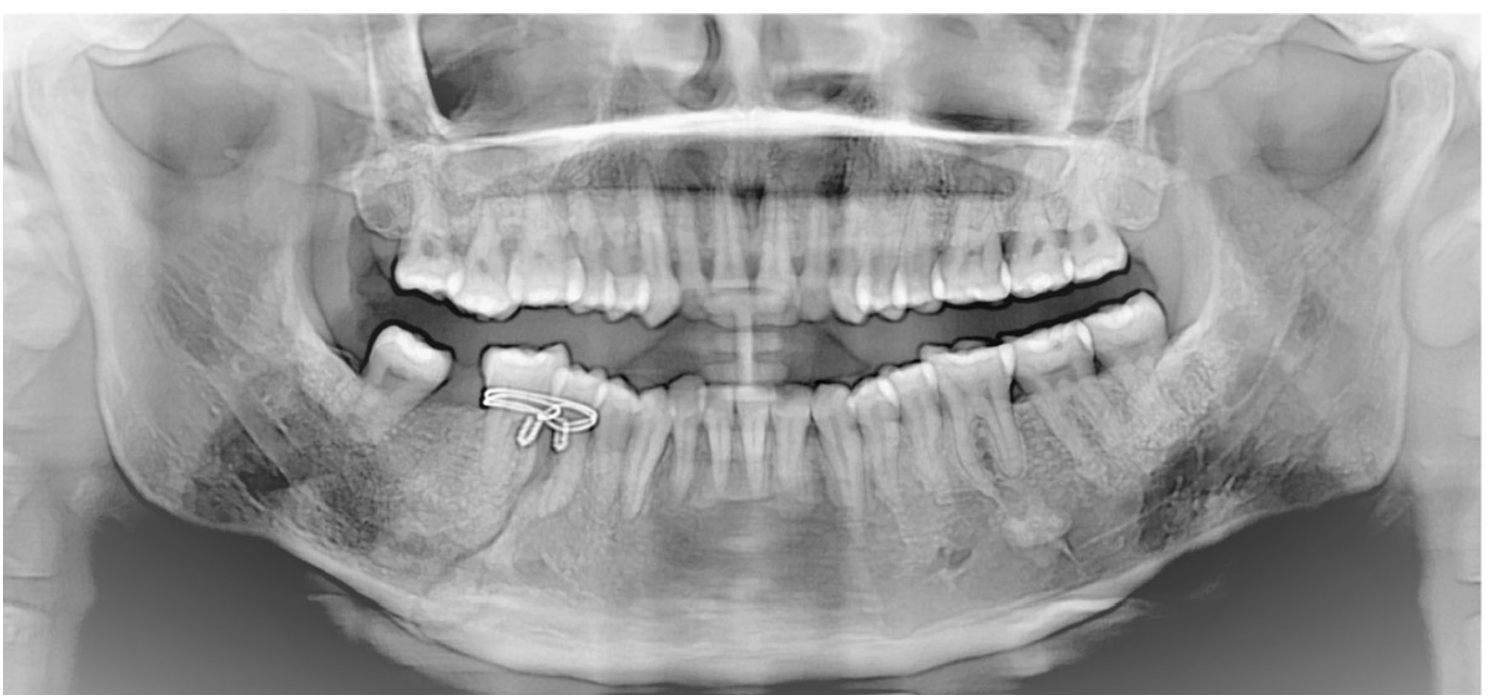

Fig. 3 Only bridle wire for a right body of mandible fracture with left subcondylar fracture

manifold when the procedure of bridle wiring is compared with that of IMF. Six weeks later when we removed the bridle wire, the patient was in good occlusion and had no segmental mobility. The other patient was a kid with a green stick fracture of the right parasymphysis region when again we used only a bridle wire for six weeks without IMF. She too had no segmental mobility after six weeks of bridle wiring. Though we employed this method for two patients, we feel indiscriminate use of this method would result in mal-union of fractures.

Three patients who had unilateral condylar head or subcondylar fractures were managed conservatively. That could have been the case even without the scenario of a pandemic. Though, at instances for a condylar fracture we do consider IMF for two weeks, sometimes with elastics for deranged occlusion. However, all these three patients had good occlusion post trauma, so we decided not to intervene.

\section{Concerns Related to the Health Care Facility}

We were going through severe shortage of inpatient beds because of the surge in patients admitted for COVID 19 treatment. Personal protective equipment was in severe short supply due to which their costs had sky rocketed. Treating isolated mandibular fractures as outpatients relieved the health care facility of so much of logistic and financial burden. Need of the hour is appropriate and judicious use of resources [18].

\section{Financial Concerns of the Patient}

The financial implications of the lockdown due to the pandemic were a major concern for the patients. In India, neither the government nor a private health insurance covers health care services for a majority of the population. Patients have to spend out of their pocket for the medical expenses. The reluctance or inability to spend for their medical expenses is obvious in the treatment choice of the patients. Sixteen of the nineteen patients with isolated mandibular fracture, which is $84.2 \%$, chose non-surgical treatment, which was financially less cumbersome and more suitable during this pandemic.

As the pandemic advanced, we made considerable progress in dealing with constraints. Preoperative testing of patients for COVID 19 was implemented as was also suggested by O' Connell $\mathrm{K}$ et al. [19]. Other measures from our institution like designated and modified operating theatres helped us overcome difficulties with respect to operating rooms. Yet the strain on health care facility with shortages of inpatient beds and inadequate amount of PPE have not been fully overcome. More importantly, the economic conditions for the patients did not improve and making out of the pocket payments for medical treatment was not affordable. Thus by adopting non-surgical treatment methods in an outpatient setting we were able to address the financial concern of the patients.

The following flowchart summarizes our treatment planning and benefits associated with it. 


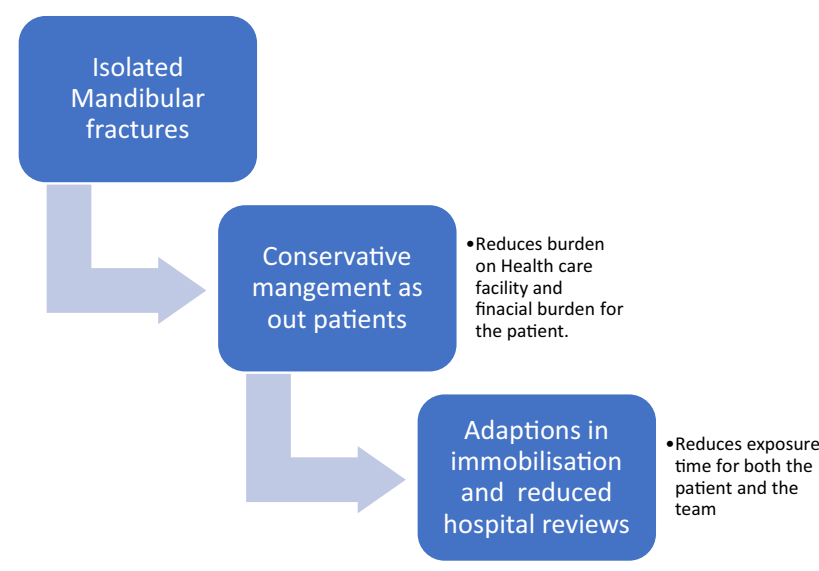

This flow chart provides the scenarios and the adaptions that were followed. adaptation that we incorporated into the process of immobilization of fracture was primarily the reduction of usage of arch bars, and instead we used only wires as they reduced the procedure duration. These treatment methods helped us tide over the crisis during the initial days of the pandemic. This deviation from the conventional treatment methods was not a desired change but was a necessity. The extent of modifications adopted in the treatment plan for each patient depended on the complexity of fracture and their presenting clinical conditions, set against the backdrop of our guidelines.

Advisories and guidelines have been constantly changing through this pandemic. We have not reached a final consensus yet! Moreover, we do not even know if we are half way through the pandemic. Nevertheless, we felt our experience would add to the database of literature on dealing with maxillofacial trauma during this pandemic.

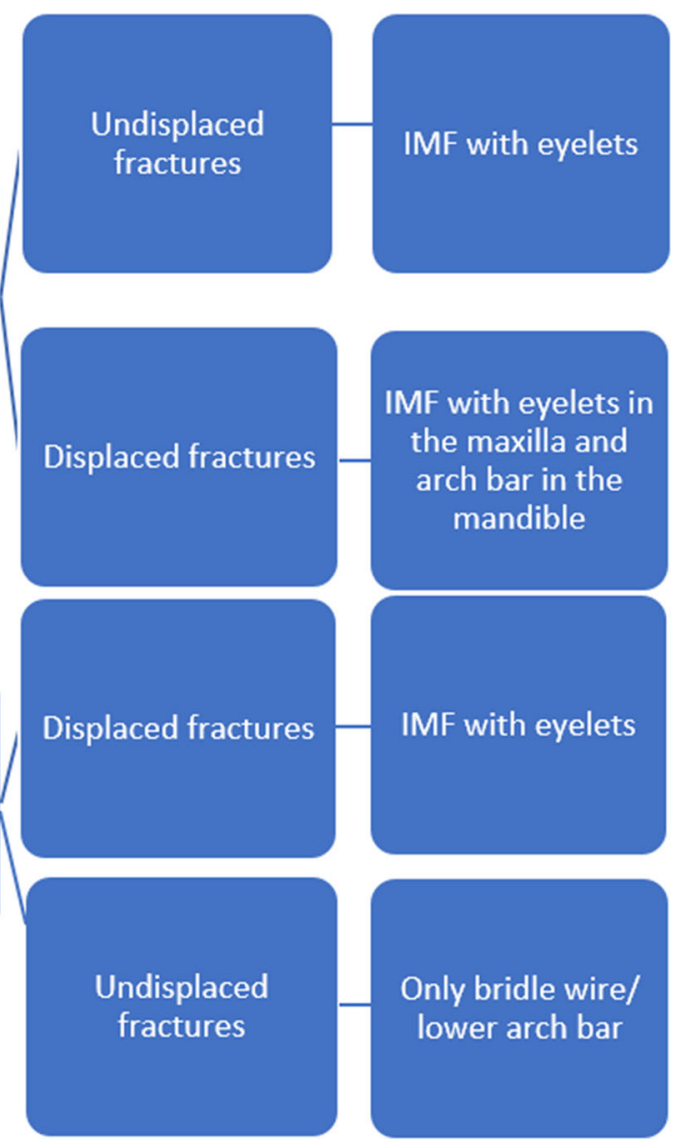

The lessons learnt and the adaptations in the treatment method to this pandemic could serve as a useful reference in the future.

Author contributions DSSS who is the first author designed the concept and framing of the guidelines. He was involved in the treatment of the patients, and he wrote the manuscript. AOG the
The guidelines that we followed helped us reduce the exposure of the patient and the health care providers to the virus; bring down the stress on the health care facility and the patients. This pandemic has taught us a few lessons in management of isolated mandibular fractures. The 
second author was involved in the treatment of the patients. JD the third author did the data collection, analysis and was involved in the treatment of the patients. VG the fourth was involved in the data collection and treatment of patients. JE the fifth author was the scientific advisor and gave inputs to the manuscript.

\section{Compliance with Ethical Standards}

Conflict of interest The authors declare no conflict of interest.

Informed Consent All the patients that were involved were informed and a written consent was obtained from them and there are no ethical conflicts involved.

\section{References}

1. Reinhart E, Reuther J, Michel C, Kübler N, Pistner H, Bill J, Kunkel E (1996) Treatment outcome and complications of surgical and conservative management of mandibular fractures. Fortschr Kiefer Gesichtschir 41:64-67

2. Virolainen E, Aitasalo K (1976) Surgical and conservative treatment of mandibular fractures: a follow-up study. Int J Oral Surg 5(6):265-269

3. Gupta H, Pradhan R, Sinha VP, Gupta S, Mehra H, Singh A (2010) Management of mandibular fracture in a medically compromised pediatric patient. Natl J MaxillofacSurg 1(2):139-142

4. Khatri A, Kalra N (2011) A conservative approach to pediatric mandibular fracture management: outcome and advantages. Indian J Dent Res 22(6):873

5. Barca I, Cordaro R, Kallaverja E, Ferragina F, Cristofaro MG (2020) Management in oral and maxillofacial surgery during the COVID-19 pandemic: our experience. Br J Oral MaxillofacSurg 58(6):687-691

6. Ghai S (2020) Facial trauma management during the COVID-19 era: a primer for surgeons. Curr Med Res Pract. https://doi.org/10. 1016/j.cmrp.2020.07.011

7. AdvisoryforHospitalsandMedicalInstitutions.pdf. Cited 2020 Aug 18. https://www.mohfw.gov.in/pdf/AdvisoryforHospitalsandMedi calInstitutions.pdf
8. DentalAdvisoryF.pdf. Cited 2020 Aug 18. https://www.mohfw. gov.in/pdf/DentalAdvisoryF.pdf

9. Ranney ML, Griffeth V, Jha AK (2020) Critical supply shortages - the need for ventilators and personal protective equipment during the Covid-19 pandemic. N Engl J Med 382(18):e41

10. Travin MS (1948) Early maxillo-facial surgery, world war II. PlastReconstrSurg 3(2):209-221

11. Gibbons AJ, Baden JM, Williams MD (2004) Oral and Maxillofacial Surgery. J R Army Med Corps 150(3):205-207

12. Holmes S, Hutchison I, Chatzopoulou D (2020) Broken jaws in the COVID era. Br Dent J 228(7):488-488

13. Koshy JC, Feldman EM, Chike-Obi CJ, Bullocks JM (2010) Pearls of mandibular trauma management. SeminPlastSurg 24(4):357-374

14. Transmission of SARS-CoV-2: implications for infection prevention precautions. Cited 2020 Aug 18. https://www.who.int/ news-room/commentaries/detail/transmission-of-sars-cov-2-impli cations-for-infection-prevention-precautions

15. Ather A, Patel B, Ruparel NB, Diogenes A, Hargreaves KM (2020) Coronavirus disease 19 (COVID-19): implications for clinical dental care. J Endod 46(5):584-595

16. Yang Y, Soh HY, Cai ZG, Peng X, Zhang Y, Guo CB (2020) Experience of diagnosing and managing patients in oral maxillofacial surgery during the prevention and control period of the new coronavirus pneumonia. Chin J Dent Res Off J Sci Sect Chin StomatolAssoc CSA 23(1):57-62

17. de Almeida Barros Mourão CF, Javid K, Bastos Barbosa I (2020) How can we reduce the risks of SARS-CoV-2 (COVID-19) for dentists and their patients? Evid Based Dent 21(2):50-51

18. Holmes S, Bhatti N, Bhandari R, Chatzopoulou D (2020) Toward a consensus view in the management of acute facial injuries during the Covid-19 pandemic. $\mathrm{Br} \mathrm{J}$ Oral MaxillofacSurg 58(5):571-576

19. O' Connell K, Fitzpatrick F, Richmond A, Foley M, Martin F (2020) Re: testing recommendation for COVID-19 (SARS-CoV2) in patients planned for surgery-continuing the service and 'suppressing' the pandemic. Br J Oral MaxillofacSurg 58(6):733

Publisher's Note Springer Nature remains neutral with regard to jurisdictional claims in published maps and institutional affiliations. 